\title{
C. W. Anderson: Todo pesquisador deve ter uma grande pergunta que vai levar décadas para ser respondida
}

Por Lívia de Souza

Vieira

Doutora em Jornalismo no Programa de

Pós-Graduação em Jornalismo da Universidade Federal de Santa

Catarina. Docente dos cursos de Jornalismo e Publicidade e Propaganda da Faculdade IELUSC.

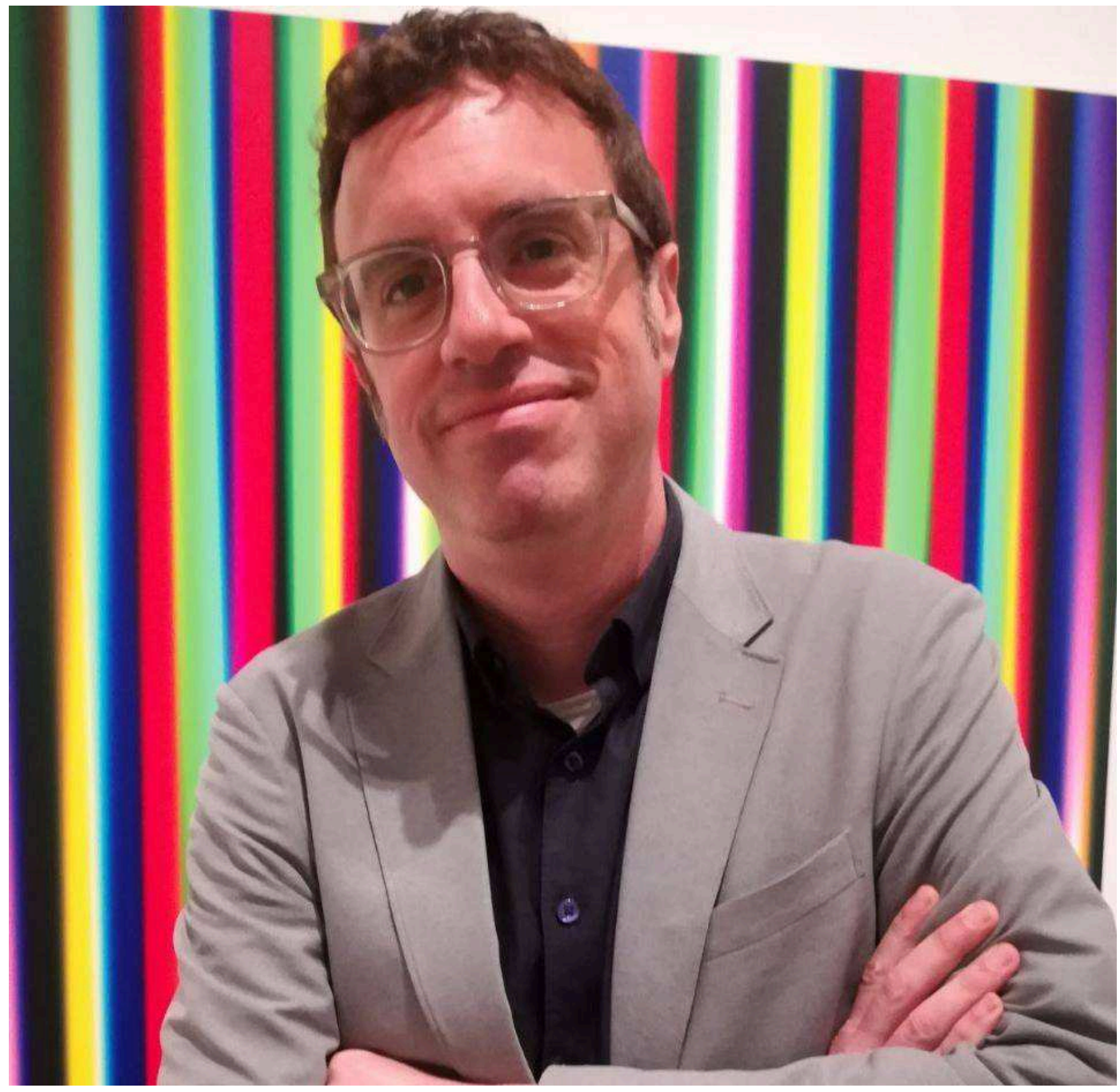

Pesquisadores em jornalismo certamente vão se lembrar desse nome. O professor C.W. Anderson é muito conhecido no país pelo Relatório do Jornalismo Pós-Industrial, escrito em 2012 com Emily Bell e Clay Shirky, da Universidade de Columbia. Mas Anderson tem outros trabalhos igualmente importantes, incluindo o mais recente: "Apostles of Certainty: Data Journalism and the Politics of Doubt" (2018), livro no qual ele analisa como a ideia de jornalismo de dados mudou ao longo do tempo. "Descobri que certos aspectos do jornalismo de dados são mais parecidos com o que eram há cem anos do que há 50", afirma.

Nesta entrevista, falamos sobre diversos assuntos como cultura do clique nas redações, etnografia (Anderson se descreve como um etnógrafo que estuda as notícias), política, crise no jornalismo e ensino. Para os pesquisadores em início de carreira, Anderson dá um conselho: "Se você tem uma grande pergunta, então torna-se menos importante se você publica muito ou pouco, porque será tudo voltado para 
respondê-la. O que acontece é que, na maioria das vezes, os acadêmicos nem sempre têm uma grande pergunta. Eles não são treinados para isso. Eles são treinados para ter perguntas pequenas".

Anderson é norte-americano e vive no Reino Unido há um ano e meio, ocupando a cadeira de professor da Universidade de Leeds. Nossa conversa aconteceu em fevereiro em seu escritório, durante uma tarde muito fria do inverno europeu.

\section{EJM - Você poderia falar brevemente sobre sua carreira? Já trabalhou como jor- nalista?}

C.W. ANDERSON - Eu nunca fui um jornalista profissional, mas trabalhei por muitos anos como um jornalista cidadão, no início dos anos 2000. Eu fazia blogs, podcasts e outras produção de mídia.

\section{EJM - Sobre que tipo de assuntos?}

C.W. ANDERSON - Em grande parte sobre política. Após o 11 de setembro estávamos vivendo um momento político importante, George W. Bush era presidente. Então eu queria contribuir de alguma forma para tentar pensar sobre o que estava acontecendo na América. Fiz isso até 2003 e depois voltei para a pós-graduação porque estava interessado na maneira como o jornalismo estava mudando. E também o que significava tantas pessoas podendo participar da mídia e como isso estava transformando o jornalismo. Naquele momento, fui para a Universidade de Columbia para trabalhar com o professor James Carey, que é famoso por sua visão da comunicação como ritual e como cultura. Infelizmente ele faleceu enquanto eu estudava. Então acabei trabalhando com Todd Gitlin e Michael Schudson. Sou certamente muito grato e muito sortudo por trabalhar com os dois. Fiz minha pesquisa inicial no ecossistema de notícias da Filadélfia, investigando como o jornalismo estava mudando por causa da Internet. Depois fui para a City University de Nova York como professor assistente, trabalhei lá por oito anos até vir para o Reino Unido como professor na Escola de Mídia e Comunicação da Universidade de Leeds.

EJM - Sua tese de doutorado é notável porque quase 10 anos atrás você observou o que chamou de cultura do clique. Desde então, os veículos jornalísticos passaram a confiar cada vez mais nas métricas de audiência, especialmente as quantitativas. Você acha que eles deveriam avaliar melhor suas decisões editoriais, já que agora sabemos que muitas dessas métricas são falsas ou não são tão confiáveis?

C.W. ANDERSON - É interessante porque uma das coisas que aprendi nas aulas em Columbia foi que os jornalistas não se importam com a audiência. Essa era uma espécie de sabedoria intelectual nas aulas de sociologia. Jornalistas eram uma comunidade profissional que não se importava com a audiência. Mas assim que cheguei à redação, eu literalmente vi pessoas com planilhas nas mãos andando, balançando-as no ar e dizendo: "Você acredita nessa história?". Eu realmente me surpreendi com o que estava acontecendo e como o que eu aprendi estava errado. Então, a questão agora é que talvez isso tenha ido longe demais: jornalistas estão muito dependentes de cliques ou de métricas e tomam muitas de suas decisões por causa dessas coisas. Por outro lado, é importante que os jornalistas saibam o que a audiência quer e o que ela precisa para ser informada. Qualquer jornalista que afirma que não precisa saber o que o público quer ler está se iludindo. Mas o jornalismo, como categoria profissional, precisa tomar decisões por si mesmo a respeito do que considera importante. É isso que faz uma comunidade profissional. É um grupo de pessoas que possui uma certa quantidade de conhecimento e, então, pode decidir por si mesma o que é importante. O jornalismo como comunidade profissional está altamente ameaçado. E isso é um problema porque é importante que os jornalistas sejam profissionais. 
Então, não acho que cliques e métricas sejam terríveis para o jornalismo. Mas acho que, na medida em que contribuem para uma maior desprofissionalização dessa ocupação tão importante, podem ser parte de uma tendência negativa. A resposta curta seria: jornalistas devem saber o que o público pensa, mas não devem se tornar escravos disso e têm que continuar pensando sobre o que a audiência precisa.

\section{EJM - Você acha que ainda hoje vivemos nessa cultura do clique ou agora a maio- ria das redações já aprendeu que cliques não explicam tudo?}

C.W. ANDERSON - Há uma lacuna real entre as organizações de notícias de elite e todos as outras. Tenho uma doutoranda que trabalhou há pouco tempo na News Corp, do Rupert Murdoch na Austrália. Ela disse que eles eram totalmente regidos por cliques, completamente governados por métricas de notícias. Mas se você conversar com algumas pessoas no The New York Times ou no The Guardian, elas dirão "bem, não, nós não somos assim, nós usamos as métricas como uma das muitas outras coisas e nós certamente não estamos vivendo nesta cultura do clique”. Mas veículos locais e mais comerciais são ainda hoje governados pelas métricas de audiência, como a News Corp e a média dos tablóides britânicos. Eu ficaria muito surpreso se eles ainda não tivessem uma visão de clickbait. Embora isso seja diferente na elite. Nas organizações de notícias de elite, que tendem a ser esse tipo de veículos que os acadêmicos estudam, não é tanto assim. Mas os jornalistas dessas redações são treinados para dizer coisas muito inteligentes. E não acho que temos etnografias suficientes para entender como tudo isso funciona - com exceção do seu trabalho, da Caitlin Petre e de algumas outras pessoas. Quando você realmente observa o que os jornalistas fazem, pode ser diferente do que eles dizem.

EJM - Você se descreve como um etnógrafo que estuda as notícias. A investigação de um etnógrafo pode entender o jornalismo em quais aspectos específicos?

C.W. ANDERSON - O objetivo da etnografia é entender como os jornalistas entendem suas vidas e seus empregos, entender o que está acontecendo com eles. Então, eu faria a diferença entre entender o que está acontecendo aos jornalistas e entender o que os jornalistas acham que está acontecendo com os jornalistas. Para um etnógrafo a chave é sempre compreender o que a pessoa pensa que está acontecendo com ela, o que ela acha que a Internet está fazendo, o que acha que a tecnologia está fazendo, o que pensa que as métricas estão fazendo. De certa forma, para um etnógrafo isso é importante, senão mais importante, do que aquilo que essas coisas estão realmente fazendo na realidade. Então, para mim, a etnografia está, em algum grau, sempre preocupada com o que poderíamos chamar de aspectos hermenêuticos da pesquisa, que é entender como as pessoas dão sentido ao mundo. Não é necessariamente entender o mundo, mas é entender como as pessoas dão sentido ao mundo. Como a etnografia permite que você passe muito tempo com as pessoas observando o que elas fazem, não apenas ouvindo o que elas dizem, há um acesso exclusivo à cultura de um lugar específico. Esse é o principal valor agregado que a etnografia traz para a pesquisa.

EJM - Neste sentido, em "Remaking the News" (2017) você propõe uma etnografia genealógica. A ideia é tentar preencher uma lacuna nas pesquisas em jornalismo que usam a etnografia como método?

C.W ANDERSON - Sim. Eu, como alguém que estuda coisas, espaços, lugares e profissões que mudaram muito rapidamente, sempre pensei se minha etnografia faria sentido dez anos depois, se ainda seria relevante e válida. E então pensei em combinar etnografia e história - não história de 100 anos atrás, mas história de 10 anos atrás. Porque a forma como as redações eram em 2009 é muito diferente do que são 
em 2019. As mudanças foram muito rápidas. A ideia era: e se combinássemos uma perspectiva histórica com uma perspectiva etnográfica? Assim, podemos observar como o caminho da redação ou o caminho do jornalismo muda à medida em que passa pelo tempo.

\section{EJM - É um enorme desafio, como colocar isso na história... Como fazer? Duran- te as entrevistas, a observação ou é preciso fazer pesquisas com antecedência?}

C.W. ANDERSON - Eu acho que é tudo isso. Certamente nas entrevistas, e você também deve fazer o máximo possível de pesquisas históricas antes de chegar. Então, uma das coisas que fiz na tese ("Rebuilding the News", 2013) foi passar muito tempo no archive.org, que é uma coleção de sites históricos. Eu pude ver como os sites eram em 2005 e antes disso. Passei muito tempo investigando isso antes de chegar lá, então eu pude pelo menos começar a ter uma noção de como essas coisas mudaram com o tempo. Eu estava apenas tentando aprender sobre como o jornalismo na Filadélfia havia mudado ao longo do tempo. Talvez houvesse algum livro acadêmico sobre isso ou algum tipo de história oral ou algo assim. E, com base nisso, sempre me interessei por entrevistas para tentar fazer as pessoas falarem sobre como suas vidas mudaram ao longo do tempo.

EJM - E neste capítulo você também diz que há uma lacuna inclusive na história da pesquisa etnográfica...

C.W. ANDERSON - Sim, e a lacuna é temporal. Em se tratando de tecnologia digital, o que aconteceu há cinco anos é história. Precisamos estar muito conscientes disso e sempre lembrar que nossa desorientação atual pode ser compreendida, em algum grau, observando o período de tempo histórico.

\section{EJM - É o que você faz no novo livro [Apostles of Certainty]?}

C.W. ANDERSON - Isso é exatamente o que eu tento fazer. No novo livro, eu realmente queria fazer esse percurso histórico. Todo mundo está falando sobre jornalismo de dados, é um tema muito quente. O livro termina com um capítulo etnográfico, mas todo o resto é histórico no sentido de que eu estava tentando entender: algo como o jornalismo de dados existia há cem anos? E se sim, como era? Como foi diferente do que é agora? Foi o mesmo que agora? Para nos ensinar sobre como a ideia do que o jornalismo de dados é mudou ao longo do tempo ou como a cultura do jornalismo de dados mudou ao longo do tempo.

\section{EJM - E o que você descobriu?}

C.W. ANDERSON - Descobri que o jornalismo de dados de hoje, em 2019, é mais parecido com o de 1899 do que o de 1970. Certos aspectos do jornalismo de dados são mais parecidos com o que eram há cem anos do que há 50. Isso porque a nossa compreensão dos dados mudou e nossa compreensão do que entendemos por dados mudou. A ideia de big data levou a muitas mudanças também. De certa forma voltei um pouco ao passado para entender o presente.

EJM - Em 2012 você lançou com Emily Bell e Clay Shirky o Relatório do Jornalismo Pós-Industrial, que é um trabalho muito conhecido no Brasil. Você poderia contar brevemente como ele foi desenvolvido entre vocês três?

C.W. ANDERSON - Claro. Michael Schudson e Leonard Downie escreveram em 2009 um relatório chamado "The Reconstruction of American Journalism" (2009), sobre tudo o que estava errado na indústria do jornalismo norte-americano na 
época. Depois disso Emily Bell foi nomeada diretora do Tow Center da Universidade de Columbia. Acho que ela queria começar com um grande projeto e pensava, até certo ponto, que o relatório falava sobre o que estava acontecendo naquele momento, mas não muito sobre o que poderia acontecer no futuro. E não era necessariamente muito prático a respeito do que a indústria de notícias deveria fazer. E ela também queria escrevê-lo com outras pessoas, então convidou a mim e a Clay Shirky para escrevermos juntos. Eu estava muito interessado nessa grande oportunidade. O relatório foi em grande parte baseado em entrevistas, um pouco de análise de conteúdo de diferentes redações e relatórios. Também tivemos um grupo de discussão que trouxe diferentes profissionais da indústria para Columbia e fizemos conversas com quatro ou cinco pessoas ao mesmo tempo. Mas era mais um relatório do que um trabalho acadêmico, eu diria. Escrevemos para acadêmicos, mas também para jornalistas e publishers.

\section{EJM - Hoje você ainda concorda com esse conceito de jornalismo pós-industrial?}

C.W. ANDERSON - A resposta curta é sim, concordo. A ideia, quando escrevemos o relatório, era de que o jornalismo pós-industrial é um estado de coisas caótico e muito instável, ao contrário do jornalismo industrial, que era relativamente estável, pois as formas de fazê-lo estavam relativamente definidas. E eu acho que a mudança que vamos ver agora é que o jornalismo pós-industrial acabará sendo como o jornalismo antigo, ou seja, ele se estabilizará. Nós não estaremos em um estado de caos para sempre. Eventualmente novas estruturas, novas rotinas, novos códigos profissionais, novas práticas organizacionais se solidificarão. Eu não acho que exista algo inerente à Internet que indicaria um estado de caos permanente. Dito isso, se você me perguntasse há um ano qual seria o novo modelo, eu provavelmente teria dito BuzzFeed ou Vice. Mas eles também estão passando por enormes dificuldades. Então, talvez o caos dure mais tempo do que eu pensava, porque pareceu-me há dois ou três anos que estávamos começando a ver alguma estabilidade.

\section{EJM - E o modelo de membership, como o The Correspondent, pode dar certo?}

C.W. ANDERSON - Jay Rosen certamente fez um tremendo trabalho em trazer esse projeto e transformá-lo em uma maneira realmente viável de fazer jornalismo. É interessante porque eles ainda não produziram nenhum jornalismo. E Jay disse isso: "Nós somos o site de jornalismo de maior sucesso que nunca produziu uma matéria". Eles tiveram muito sucesso até agora, mas acho que eventualmente eles têm que fazer jornalismo e você sabe que fazer jornalismo é complicado. $\mathrm{E}$ até certo ponto é mais fácil querer apoiar algo quando você não sabe o que vai acontecer. O complicado para o The Correspondent será sua capacidade de manter esses assinantes. Tomara que consigam, vamos ver. Então, minha resposta sobre se eles são um modelo, acho que é cedo para dizer.

\section{EJM - Além disso, a América é um mercado diferente da Holanda...}

C.W. ANDERSON - Sim, absolutamente. É um mercado maior. O problema nos Estados Unidos é que o jornalismo lá tradicionalmente tem sido muito local, historicamente porque a América é muito grande e também devido à sua natureza federalizada, na qual as decisões são tomadas localmente. Por causa disso, o jornalismo tem sido local e não há um modelo de negócios para os jornais locais nos EUA, quero dizer, parece que não existe ainda. Então a questão lá é: o que vai acontecer com o jornalismo local? O jornalismo nacional é apenas Trump o tempo todo, é o mais recente escândalo político que explode e se torna notícia por 48 horas. Hoje o modelo de negócios das notícias nos EUA parece ser Trump e escândalos políticos contínuos. Mas isso é sustentável ou todos vão enlouquecer? Muitas das notícias têm ritmos similares, como 
uma coisa estúpida que Trump disse hoje, o que Bob Mueller está fazendo... Hoje o governador da Virgínia falou coisas racistas e eu garanto que em um mês haverá algum outro político que também tenha feito algo. Não significa que essas coisas não sejam importantes. Mas você tem que se perguntar quanto tempo podemos manter isso antes que as pessoas tenham um colapso nervoso.

EJM - No Brasil estamos enfrentando a mesma coisa com o novo presidente. Bolsonaro também posta polêmicas no Twitter o tempo todo e não gosta de falar com a imprensa. O que o Brasil pode aprender com o jornalismo americano em relação a essa questão?

C.W. ANDERSON - Acho muito difícil para a imprensa nos EUA saber o que fazer quando ela se torna alvo de um tipo particular de ataque político. Trump fez da imprensa americana seu inimigo. E suspeito que o novo presidente brasileiro fará o mesmo ou já fez. A questão é como você responde. E isso é algo que Jay Rosen também falou muito. Você pode responder dizendo "não, nós não somos o inimigo, somos apenas jornalistas objetivos fazendo o nosso trabalho", o que eu acho que é a escolha errada. Ou você diz que "na medida que o presidente é contra ideais democráticos básicos, nós somos seus inimigos". Isso é diferente de dizer que vamos tomar partido, que vamos apoiar os Democratas, Liberais ou o Partido dos Trabalhadores. O que você pode dizer como imprensa é "somos a favor da verdade. Somos a favor da bondade. Somos a favor de conversas razoáveis, da capacidade de discordar. Somos contra o racismo. Somos contra as ditaduras". Para mim, isso é diferente de dizer que somos a favor de um determinado partido político. Significa dizer que estamos do lado de certos ideais e na medida que temos uma liderança que viola esses ideais, então somos seus inimigos. E acho que isso é algo que a imprensa brasileira pode aprender com a imprensa norte-americana.

EJM - Tenho visto você e outros pesquisadores postando no Twitter sobre a carreira acadêmica, sobre o número de artigos em revistas que as universidades exigem e se é possível construir uma carreira saudável e ao mesmo tempo produtiva. Você acha que devemos publicar menos?

C.W. ANDERSON - Essa é uma ótima pergunta. O que eu diria a um pesquisador em início de carreira é o seguinte: no final, o mais importante é que você tenha uma grande pergunta que levará algumas décadas para ser respondida. Então, se há uma grande pergunta, torna-se menos importante se você escreve muito ou um pouco ou se às vezes você bloga, você tuita ou escreve livros ou trabalhos acadêmicos, porque é tudo voltado para responder a grande questão. O que acontece é que, na maioria das vezes, os acadêmicos nem sempre têm uma grande pergunta. Eles não são treinados para isso. Eles são treinados para ter perguntas pequenas. E quando você tem perguntas menores, tudo que você pode fazer é publicar. Se você tiver uma grande pergunta e estiver sempre tentando respondê-la de formatos e métodos diferentes, você publicará exatamente a quantia certa. Não será preciso se preocupar se está atingindo sua cota. Eu tenho uma grande pergunta desde que comecei.

\section{EJM - E qual é a sua grande pergunta?}

C.W. ANDERSON - Minha grande pergunta é: como sabemos o que sabemos para operar como cidadãos democráticos? E que tipos diferentes de profissões nos dizem o que sabemos e como nos dizem o que sabemos de diferentes maneiras? Essa é a minha grande questão. Como sabemos o que sabemos, o que não quer dizer "existe uma realidade?", mas descobrir como diferentes tipos de instituições e pessoas operam de uma forma liberal democrática, como elas interagem. E o jornalismo é uma dessas instituições, uma das principais. Mas também a Academia e seus vizinhos, 
suas redes sociais. Então o jornalismo é realmente importante, mas também uma das coisas sobre minha própria pesquisa é que o jornalismo nunca foi o único foco. $\mathrm{E}$ considero isso um problema para os pesquisadores de jornalismo, eles se importam demasiadamente - e somente - com o jornalismo.

\section{EJM - Quais são os grandes desafios para o ensino de jornalismo hoje em dia?}

C.W. ANDERSON - Há uma resposta intelectual e há uma resposta profissional para isso. A resposta intelectual é como você equilibra seu próprio julgamento profissional sobre o que a audiência precisa saber versus a necessidade de responder ao que ele quer saber. E como você, professor, ensina os alunos a navegar nesse mundo onde eles serão inundados com informações sobre o que a audiência quer. E a resposta profissional é o que devemos aos nossos alunos quando os ensinamos sobre uma profissão que está em sérios problemas? Que nível de honestidade nós devemos a eles? Se seus alunos são como os meus, muitos deles são muito idealistas, apaixonados, muito jovens e têm essa visão do que querem fazer e por que querem estudar jornalismo. E é sempre uma questão complicada, como você mantém isso, como você inculca essa paixão neles, mas também não os ilude a pensar que essa vai ser uma vida fácil ou que será uma maneira fácil para eles ganharem a vida.

EJM - E é difícil porque eles chegam na universidade sabendo lidar com todos os gadgets, mas como você explica que o jornalismo não é apenas isso, é preciso conversar com as pessoas e fazer perguntas difíceis...

C.W. ANDERSON - Não é incrível a quantidade de estudantes que querem fazer jornalismo e não gostam de conversar com pessoas? Todo ano isso me choca. Eu acho que a chave para ser jornalista é que você tem que gostar das pessoas. E isso é uma das coisas torna a etnografia e o jornalismo semelhantes. Em última instância, muitos acadêmicos não gostam de pessoas também. A Academia é uma boa carreira se você não gosta de pessoas porque pode ir à biblioteca e trabalhar sozinho. Mas se você quer fazer pesquisa etnográfica você tem que ser diferente, como um jornalista deveria ser. 